\title{
Exploring the Physical Properties of 3D Printed Recycled Carbon Fiber
}

\author{
Peng Hao Wang*, Garam Kim, Ronald Sterkenburg and Natalie Zimmermann \\ School of Aviation and Transportation Technology, Purdue University, USA
}

Submitted: July 20, 2020; Published: July 28, 2020

*Corresponding author: Peng Hao Wang, Assistant Professor, School of Aviation and Transportation Technology, Purdue University, 1401 Aviation Drive, West Lafayette, Indiana, USA

\begin{abstract}
Composite materials have experienced a rise in popularity as they are incorporated by many aerospace manufacturers as the material of choice for large airframe designs and structures. However, even though composite materials present a wide variety of benefits when compared to traditional aerospace alloys, their increased utilization has also led to new challenges related to the handling of the composite waste that is generated throughout their lifecycle. Composite waste can range from leftover scraps resulting from the manufacturing process to entire airframe sections that have passed their useful life. As the popularity of composite materials shows no signs of slowing, the management and recycling of composite waste becomes crucial to the sustainability of the environment. One of the popular methods currently being studied to address the recycling of composite materials is three-dimensional (3D) printing, especially due to its low cost, short fabricate times, and its ability to maintain low material waste. In this study, a team of faculty and students from Purdue University's School of Aviation and Transportation Technology (SATT) explored the physical properties of 3D printed recycled carbon fiber. Multiple specimens were fabricated from randomly selected sections of a prototype 3D printed recycled carbon fiber part, and the physical properties thereof, such as void content, fiber content, fiber length, fiber orientation, and curing stage, were determined. The data collected from this study provides valuable information in the understanding of 3D printed recycled carbon fiber and highlights potential improvements for future 3D printing processes.
\end{abstract}

Keywords: Carbon fiber; Physical properties; Optical microscopy; Recycling; 3D printing

\section{Introduction}

In the aerospace industry, the early adoption of composite materials was primarily limited to secondary aircraft structures [1]. However, as the knowledge of these materials increased and the techniques of use thereof began to mature, composite materials gradually became the material of choice for many aerospace manufacturers. Today, composite materials are the standard material choice for many large and critical airframe structures, thus replacing aerospace alloy materials such as aluminum and titanium as the only materials of choice for the design and fabrication of said structures [2]. As the application and use of composite material technology continues to increase, the popularity of composite materials shows no signs of curbing soon. However, the increased utilization and popularity of composite material does present a drawback-The increased use of composite materials has resulted in, and thus is accompanied by, an increased amount of composite waste.

A large volume of the fibers and polymers used in today's composite materials are artificial and manmade, and as such do not decompose naturally. Consequently, the recycling of composite waste has proven to be a challenging and expensive task, causing the proper management and recycling of these materials to become an increasingly critical element to the sustainability of the aerospace industry and the environment [3]. In anticipation of the emerging composite waste issues, many countries, including New Zealand, Lebanon, and China, as well as large business organizations, such as DuPont, Hewlett Packard, NEC, and Toyota, have already adopted the zero-waste philosophy [4]. As the global community continues to strive for greener solutions and notions such as the zero waste philosophy are adopted, it is vital for the aerospace industry to support the efforts to tackle the emerging sustainability concerns by developing potential composite waste recycling strategies.

In this study, a team of faculty and students from Purdue University's School of Aviation and Transportation Technology (SATT) analyzed 3D printing technologies as an approach to composite waste recycling. 3D printing recently garnered a lot 
of attention and has experienced an increase in use due to the technology's ability to repurpose recycled composite fibers for the fabrication of alternative prototype and production components. Another factor adding to 3D printing's popularity, is the technology's relatively low material waste, low cost, and short processing times $[5,6]$. This study aimed to investigate the physical properties of 3D printed recycled carbon fiber. Specifically, physical properties such as void content, fiber content, fiber length, fiber orientation, and curing stage throughout different sections of a prototype 3D printed recycled carbon fiber part were examined.

\section{Materials and Methods}

A prototype 3D printed recycled carbon fiber part shown in Figure 1 was used for the fabrication of the specimens used in the study. Specifically, the specimens were fabricated from randomly selected sections of the prototype 3D printed recycled carbon fiber part. A total of twelve $25.4 \mathrm{~mm}$ long specimens were sectioned from the 3D printed prototype part via the use of a precision diamond saw shown in Figure 2. The specimens were then inserted into molds, which were filled with clear resin. The resin was left to cure, and once cured, the specimens were subjected to a series of surface polishing sequences. The purpose of the surface polishing as shown in Figure 3 was to remove any surface imperfections from the specimens, thus enhancing the quality of the microscopic images for analysis.
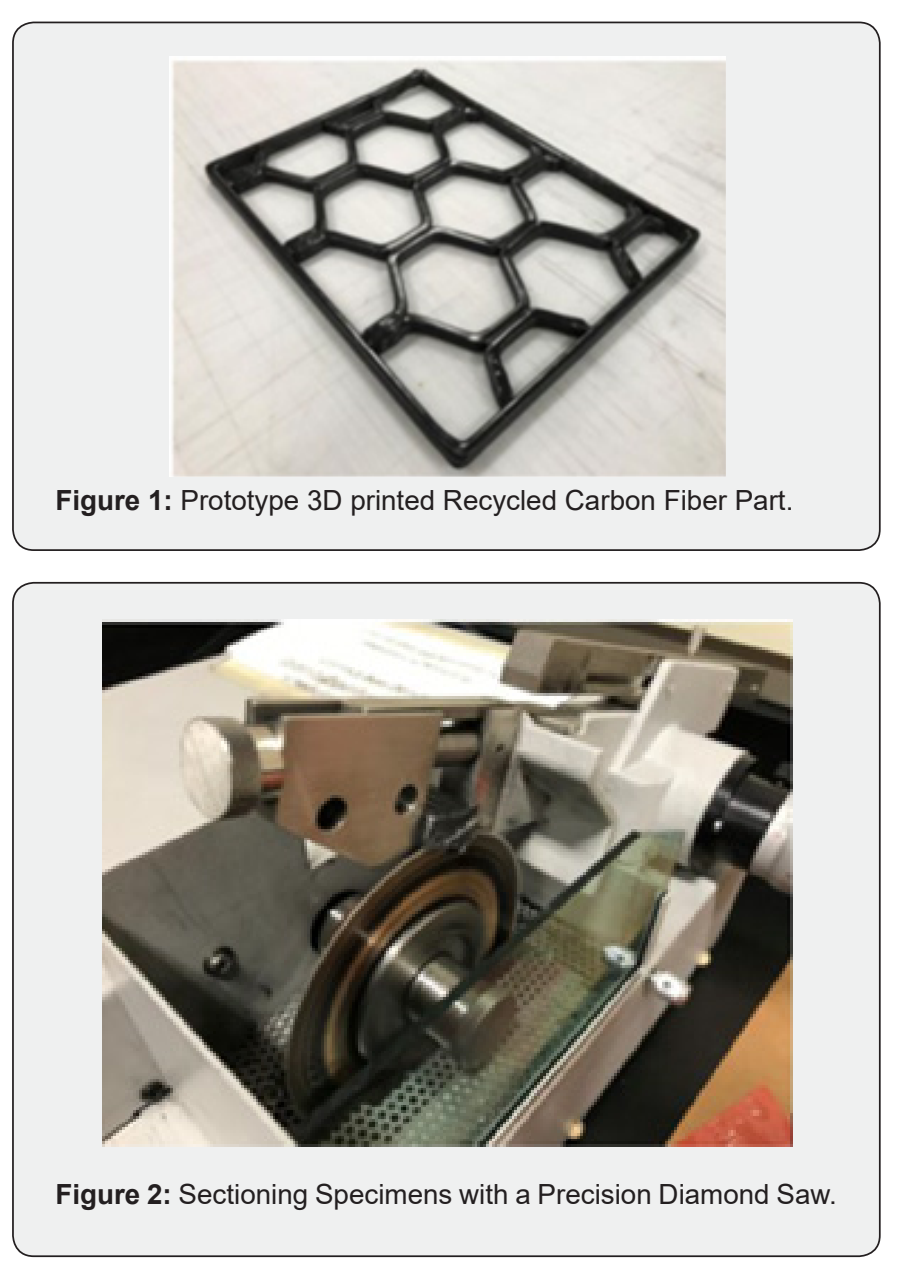

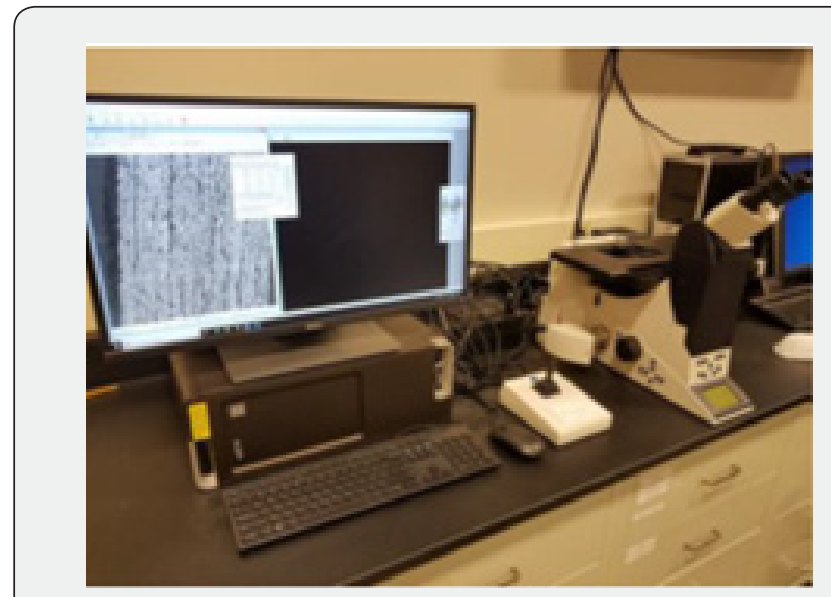

Figure 3: Specimen Microscopy Imaging.

The microscopic images collected from the specimens were studied using ImageJ image analyzing software, with the purpose of examining the void content, fiber content, and fiber orientation of the specimens. In order to study and test the fiber length of the prototype 3D printed recycled carbon fiber part, additional $25.4 \mathrm{~mm}$ long specimens were randomly sectioned from the prototype part. These $25.4 \mathrm{~mm}$ specimens were placed in a furnace and heated for a total of 120 minutes at $600^{\circ} \mathrm{C}$. Once the furnace heating cycle was completed, the remaining ashes of the specimens as shown in Figure 4 were gathered from the furnace and directly placed onto microscope slides. Spreading out the fibers is a critical step and care has to be taken as the image analysis may be difficult or inaccurate if the ashes are not effectively spread out. A drop of acetone was applied onto the ashes to aid spreading them out evenly. Once the ashes were spread out, a second microscope slide was placed on top of the ashes to complete the preparation of the microscope slides. The ashes were then examined using ImageJ image analyzing software, and the length of the fibers within the ashes of the specimens was measured as shown in Figure 5.

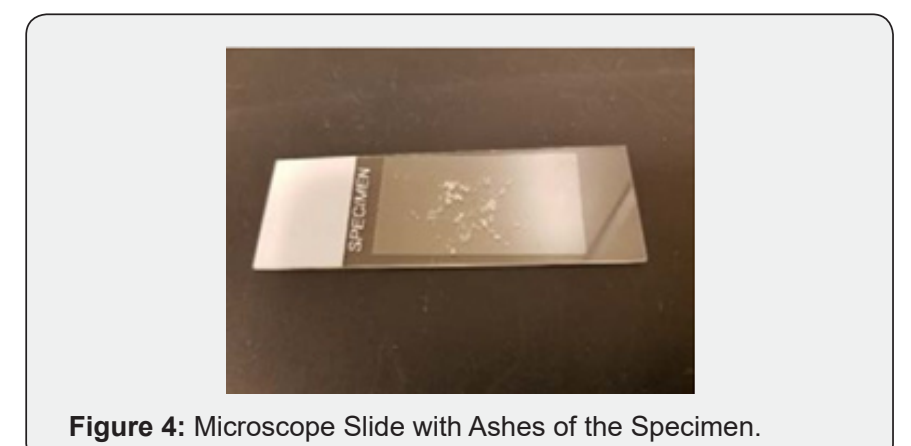

Figure 4: Microscope Slide with Ashes of the Specimen.

Two different tests were performed to determine the curing characteristics of the prototype 3D printed recycled carbon fiber part, namely differential scanning calorimetry (DSC) and dynamic mechanical analysis (DMA). The DSC test is designed to measure the heat flow of the specimens to analyze the material's thermal characteristics, including glass transition temperature, phase change, crystallization, and curing kinetics. The DMA test 
is different in that the test is designed to measure the mechanical behaviors of the specimens under temperature change. Examples of the aforementioned mechanical behaviors include storage modulus, loss modulus, and the tangent delta. To perform the DSC test shown in Figure 6, a small sample of the prototype 3D printed recycled carbon fiber part was placed inside an aluminum capsule. The aluminum capsule is then inserted into the DSC machine's test chamber. The DSC machine was programed to perform the test by beginning and first stabilizing at $25^{\circ} \mathrm{C}$. The temperature was set to raise at the rate of $25^{\circ} \mathrm{C}$ per minute to a target temperature of $200^{\circ} \mathrm{C}$. The specimen then rests at $200^{\circ} \mathrm{C}$ for 5 minutes until the temperature is gradually lowered at a rate of $25^{\circ} \mathrm{C}$ per minute, back down to $25^{\circ} \mathrm{C}$. The data gathered from the DSC test was used for the thermal analysis of the prototype 3D printed recycled carbon fiber part.
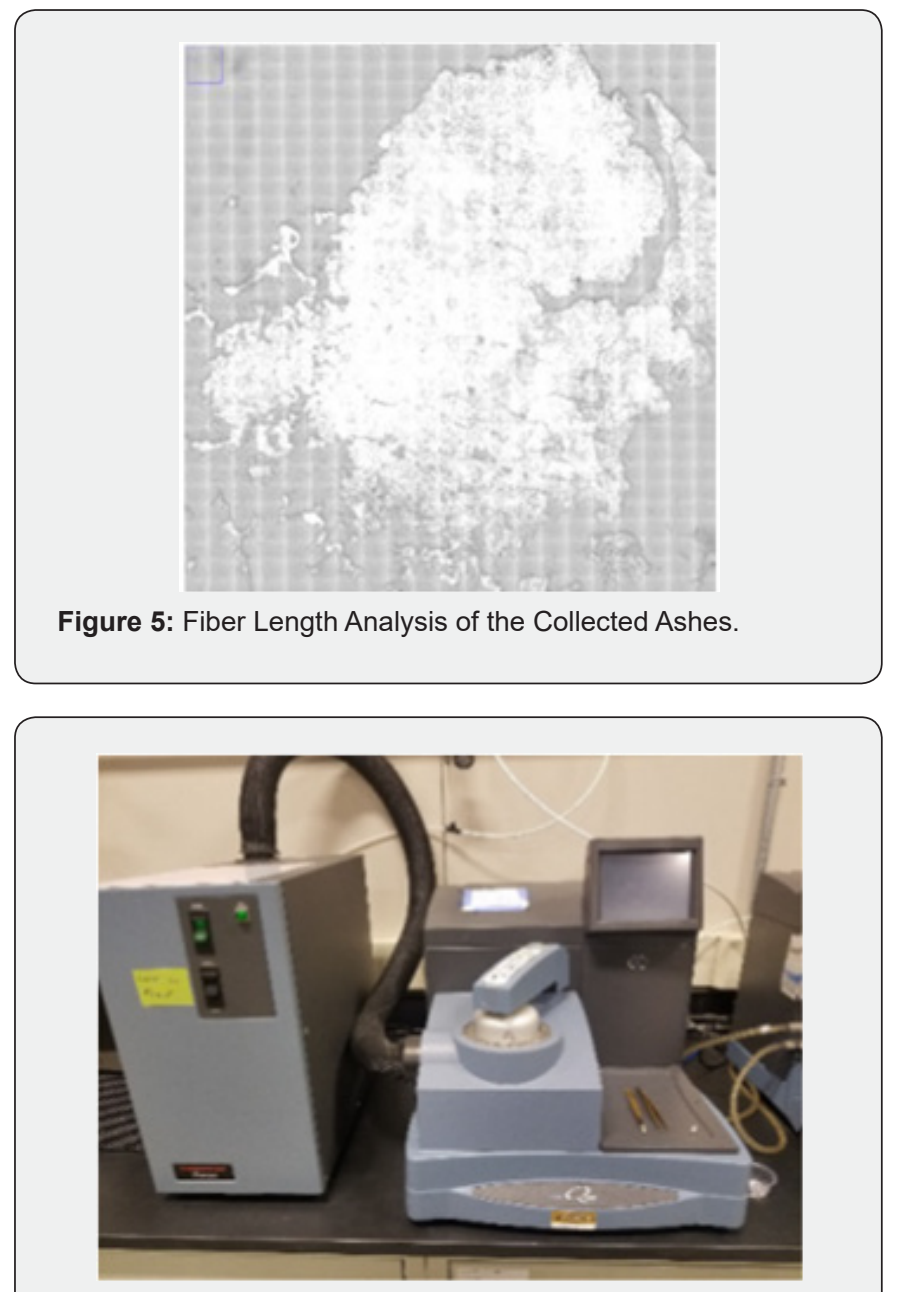

Figure 6 :Differential Scanning Calorimetry (DSC) Test.

Figure 7 shows the specimens subjected to the DMA test. The specimens were $35 \mathrm{~mm}$ long, $9 \mathrm{~mm}$ wide, and $3.32 \mathrm{~mm}$ thick. A double cantilever test fixture as shown in Figure 8 was used to perform the DMA test, with a constant amplitude temperature sweep and a constant strain rate. The temperature for the DMA test was set to increase at a constant rate of $3^{\circ} \mathrm{C}$, up to a target temperature of $150^{\circ} \mathrm{C}$. Throughout this test, the specimens were heated at a constant rate. During the heating process, the specimens were deformed at a constant strain of 0.02 over a range of frequencies.

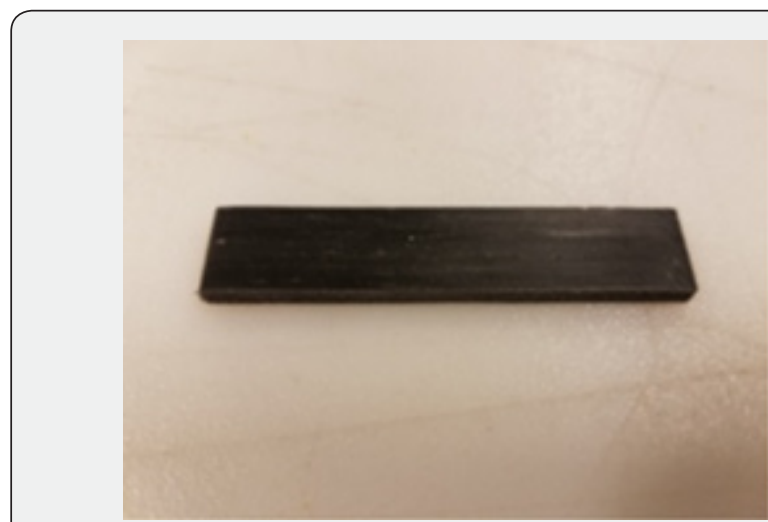

Figure 7: Dynamic Mechanical Analysis (DMA) Specimen.

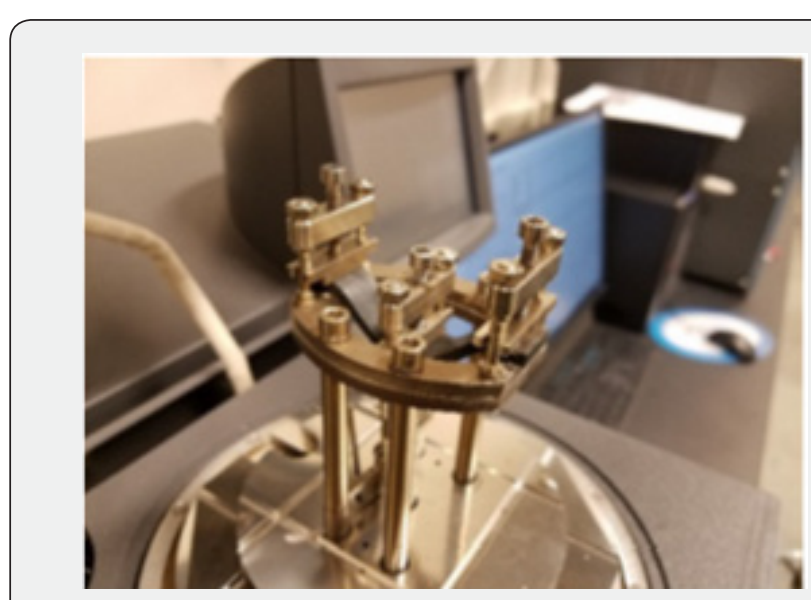

Figure 8: Double Cantilever Test Fixture for the DMA Test.

Analysis

Microscopic images of the cross-sections of the twelve specimens were collected and analyzed through a microscopy test. This analysis aims to determine three physical properties of the specimens, namely the specimens' void content, fiber content, and fiber orientation. The void content within the specimens was identified as areas covered with black pixels. The dimensions of these voids were individually measured using image analyzing software as shown in Figure 9. The void content of the specimens was calculated using the void ratio equation shown in Equation 1, where $V_{v}$ is the void content of the specimen, $\boldsymbol{\rho}_{v}$ is the area of the void, and $\boldsymbol{\rho}_{\mathrm{t}}$ is the total cross-sectional area of the specimen.

$$
V_{V}=\rho_{v} / \rho_{t} \quad \text { Equation } 1
$$

The fiber content of the specimens was determined by measuring the area of the fibers in the cross-sectional area of the specimens. Specifically, a grid composed of $500 \mu \mathrm{m}$ by $500 \mu \mathrm{m}$ areas was generated over the cross-sectional area of the specimens as shown in Figure 10, and the area of the fibers within each grid 


\section{Juniper Online Journal Material Science}

was measured. In addition, the grid method also allowed for the determination of the fiber distribution within the 3D printed beads shown in Figure 11. The fiber content of the specimens was calculated using the threshold method, where only the pixels falling within pre-determined low and high threshold values are included into the area calculation. The fiber content of the specimens was calculated by inputting the dimension calculated through the threshold method into the fiber volume fraction equation as shown in Equation 2, where $V_{f}$ is the fiber volume fraction, $\boldsymbol{v}_{f}$ is the fiber volume, $\boldsymbol{v}_{\mathrm{c}}$ is the matrix volume, $\mathrm{A}_{\mathrm{f}}$ is the area of the fiber in the cross-sectional area of the specimen, and $A_{c}$ is the area of the matrix in the cross-sectional area of the specimen.

$$
V_{f}=v_{f} / v_{c}=A_{f} / A_{c} \quad \text { Equation } 2
$$

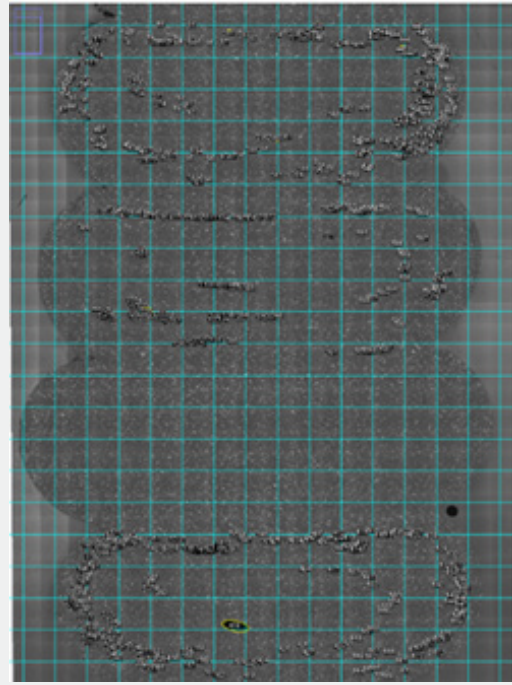

Figure 9: Image Analysis of Specimen's Void Content.

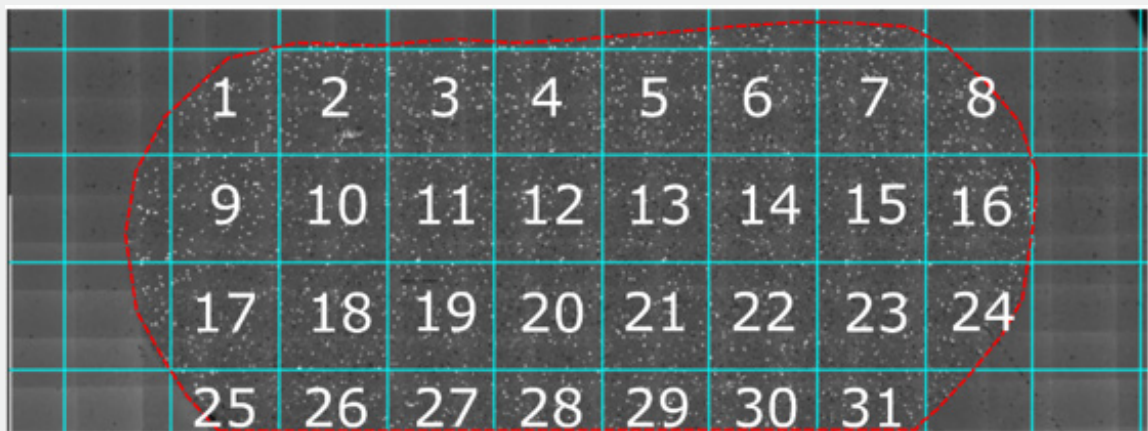

Figure 10: Image Analysis of Specimen's Fiber Content.

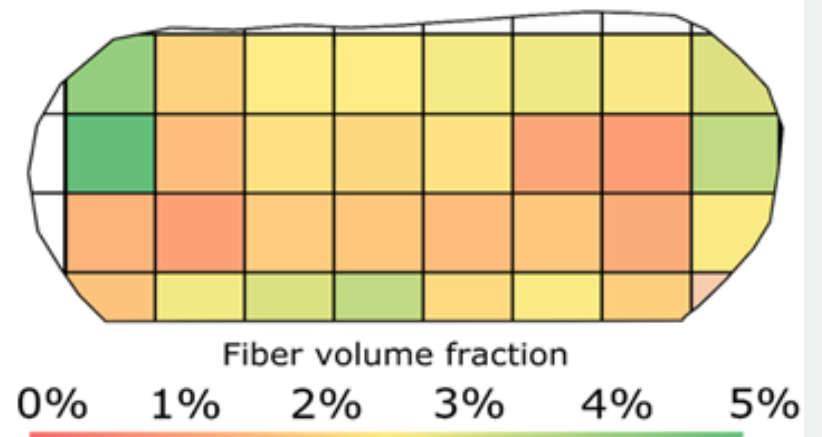

Figure 11: Example of Fiber Distribution within a Bead. 
The fiber orientation of the specimens was calculated by using $500 \mu \mathrm{m}$ by $500 \mu \mathrm{m}$ grid areas generated over the cross-sectional area of the specimens. The fiber orientation of each fiber within each grid was calculated using Equation 3, the cross-sectional shape and area of the fiber as shown in Figure 12 and Figure 13.
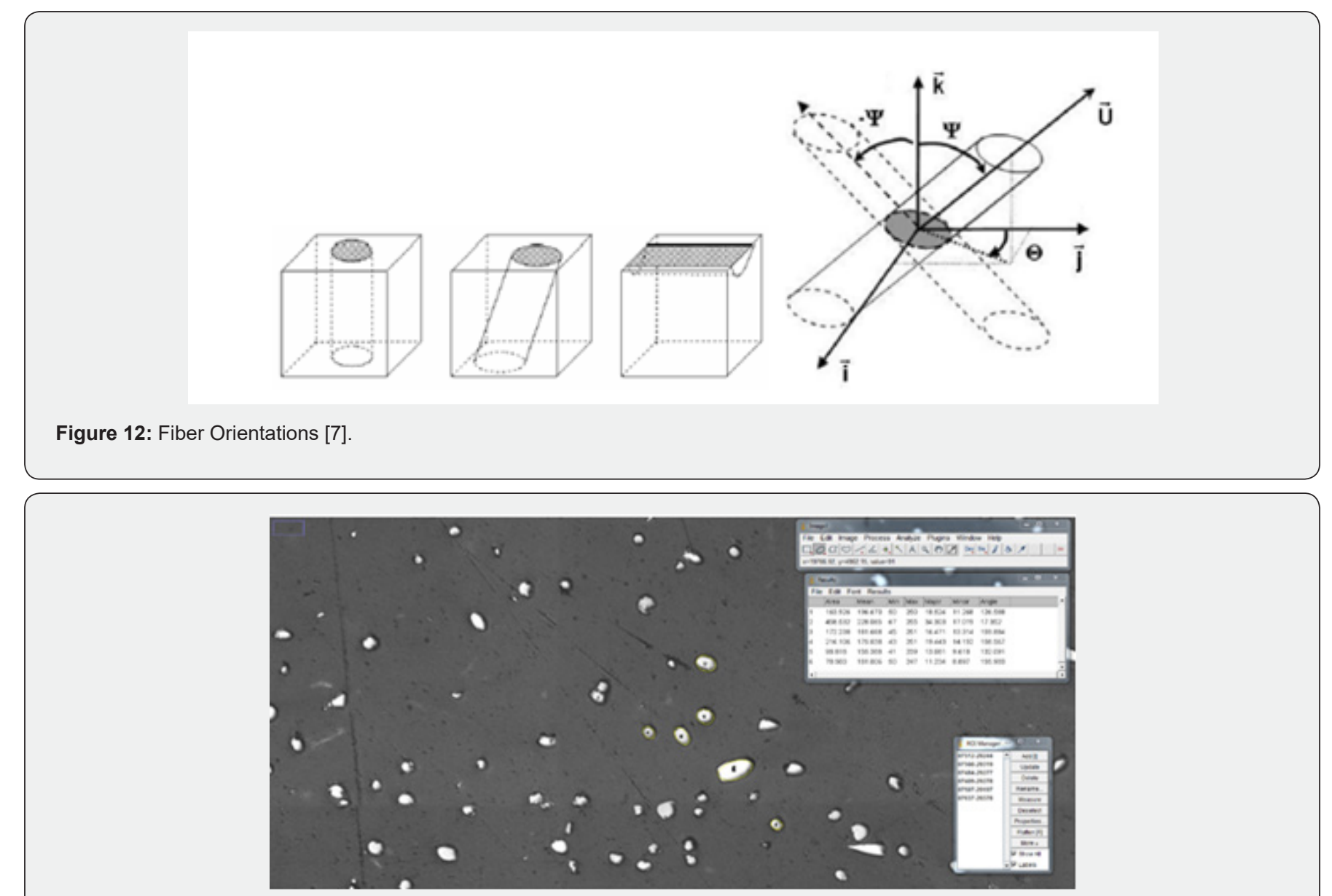

Figure 13: Microscopic Picture for Fiber Orientation Measurement.

The fiber length of the specimens was calculated by randomly selecting a total of approximately 2500 fibers. The length of each individual fiber was measured with the help of image analyzing software as shown in Figure 14. The DSC test results of the specimens were collected from a total of ten different specimens. However, the glass transition temperature $\left(\mathrm{T}_{\mathrm{g}}\right)$ of the polymer used for the prototype 3D printed recycled carbon fiber part could not be determined after the initial round of test results. Therefore, to better understand the polymer used for the 3D printing process and its $\mathrm{T}_{\mathrm{g}}$, the DSC test procedure was modified. The temperature for the DSC test was modified to first ramp downwards to $-50^{\circ} \mathrm{C}$ at a rate of $-5^{\circ} \mathrm{C}$ per minute. The specimens were left to rest at $-50^{\circ} \mathrm{C}$ for 5 minutes before the temperature was increased again to $200^{\circ} \mathrm{C}$ at a rate of $20^{\circ} \mathrm{C}$ per minute. At $200^{\circ} \mathrm{C}$, the specimens were left to rest for 5 minutes. Finally, the temperature was lowered to a target temperature of $-50^{\circ} \mathrm{C}$ at a rate of $-20^{\circ} \mathrm{C}$ per minute. Five specimens were used to obtain DMA test results. Three different methods were used to determine the $\mathrm{T}_{\mathrm{g}}$ and melting temperature of the specimens as shown in Figure 15. The first method consists of finding the point where the storage modulus drops. The second method consists of finding the point where the loss modulus has peaked. Finally, the third method consist of finding the point where the tangent delta is at its peak.

\section{Results}

Microscopic pictures of the cross-sectional areas showed that voids in the 3D printed beads were not consistent. Some beads were observed to have more voids, while other beads had little to no voids within their cross-sectional area. However, the voids within the specimens were consistently located around the outer edge of the beads. Furthermore, more voids were observed in the bottom beads than in the top beads. The possible cause for such a void distribution could be due to the deposition of the beads-As the fibers stayed at their relative positions, the matrix 


\section{Juniper Online Journal Material Science}

gradually flowed outwards and downwards, thus moving the voids with the matrix flow. Large voids can also be found within the interface between the beads and are also most likely caused by the deposition process where voids can ingress between the beads. During the image analysis, large clusters of fibers shown in Figure 16 were also present in some of the beads. The large fiber clusters suggest that the consistency of the recycling process was not effectively controlled, as the recycled carbon fibers were not crushed into uniform sizes. From the data collected, it was determined that the average void content of all the specimens was approximately $1.40 \%$. A Grubb test was performed on the data obtained from each specimen, to ensure that the data was consistent and did not include outliners.

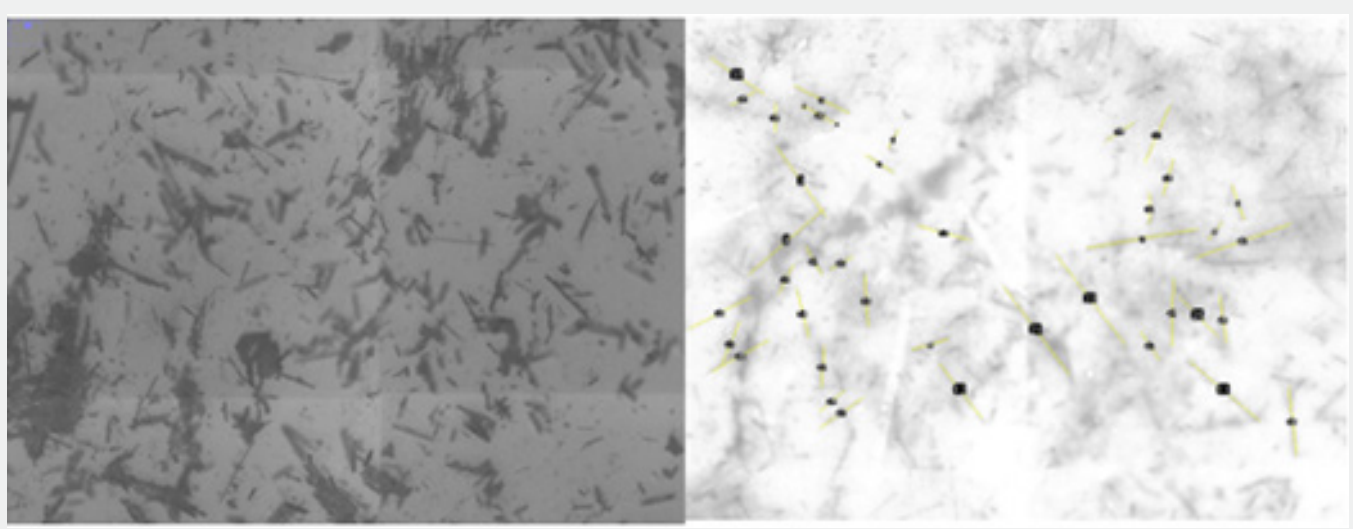

Figure 14: Image Analysis of Specimen's Fiber Length.

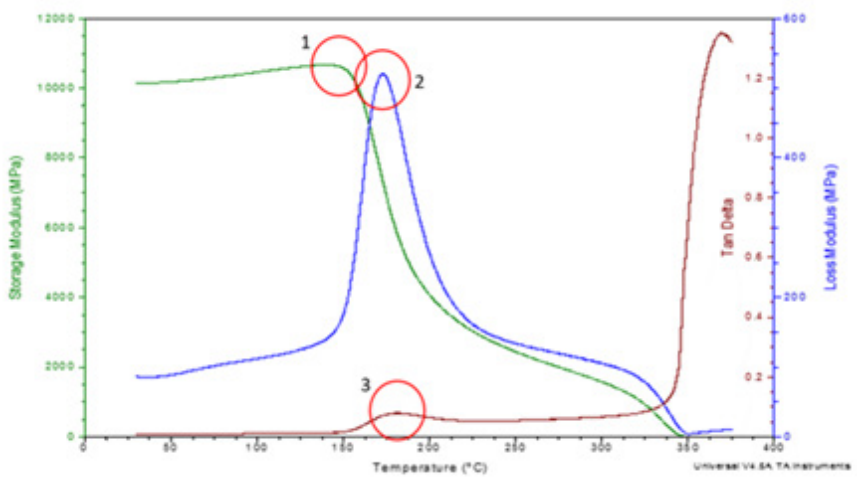

Figure 15: Sample DMA Test Result Graph.

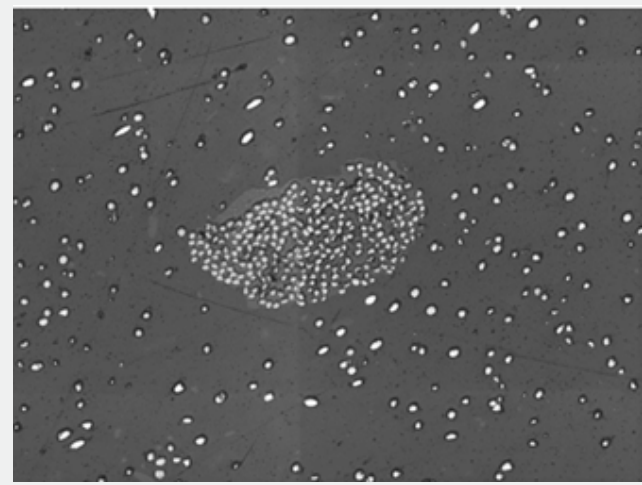

Figure 16: Fiber Clusters within Beads. 
The average fiber content was determined to be around $2.26 \%$, with the majority of the fibers distributed around the outer edge of the beads. Few fibers were distributed within the bead centers. The fiber orientation of the specimens was observed to be highly inconsistent throughout the beads as shown in Figure 17. However, it is apparent that fibers with similar orientations tend to distribute themselves closer to each other in separate clusters. The center of the beads consisted mainly of fibers oriented at around 90 degrees, with a round cross-sectional area. However, the fibers located around the outer edges of the beads were more inconsistent and included a wider range of fiber orientations shown in Figure 18. This inconsistency is mainly caused by the tampering process after the beads were deposited. During the tampering process, the fibers in the center of the beads were relatively unaffected. However, as the matrix around the outer edges of the beads deforms with the tampering process, the fibers located within the outer edge matrix shift, thus changing their orientation. The average fiber length of the specimens was determined to be around $95.87 \mu \mathrm{m}$. An ANOVA test was performed with the collected data, and the results thereof revealed that the fiber lengths in each specimen were significantly different and very inconsistent.

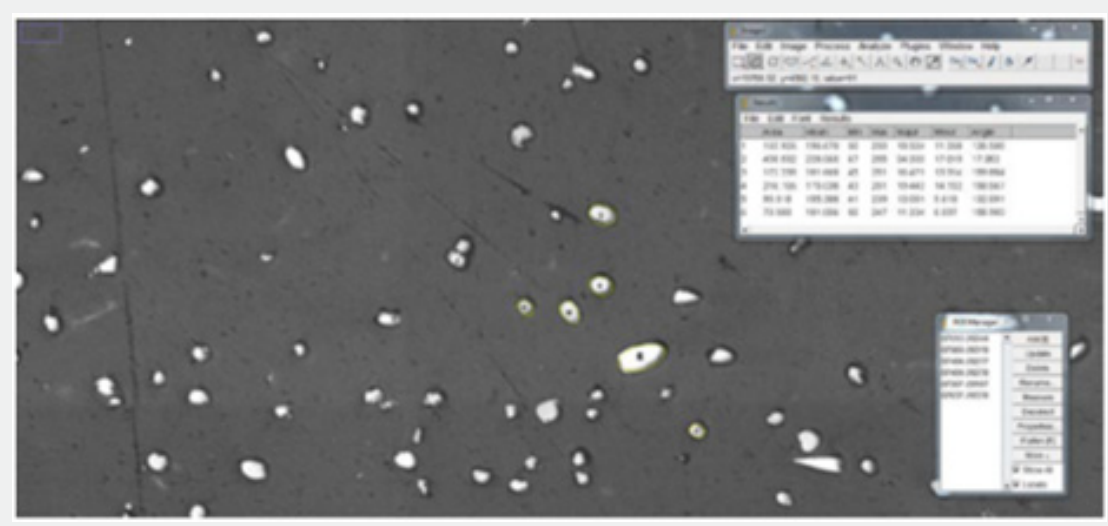

Figure 17: Image Analysis of Specimen's Fiber Orientation.

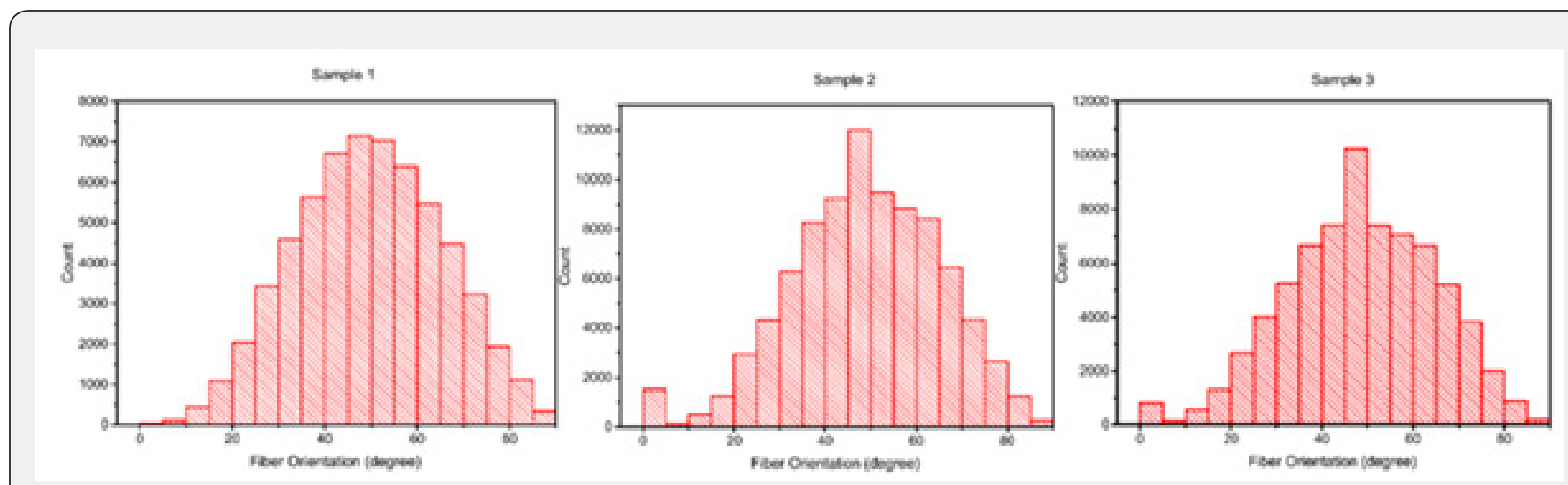

Figure 18: Specimen Fiber Orientations.

The initial DSC results shown in Figure 19 showed two different melting stages and two crystallization stages. The first average melting point of the specimen was determined to be $105.96^{\circ} \mathrm{C}$, while the second average melting point was determined to be $133.13^{\circ} \mathrm{C}$. The first average crystallization point of the specimen was at $126.60^{\circ} \mathrm{C}$, while the second average crystallization point was at $105.70^{\circ} \mathrm{C}$. The multiple melting and crystallization stages suggest that the polymer used for the $3 \mathrm{D}$ printing process may have been a blend between two or more different materials. A
Grubb test was performed, and the results showed consistent data with no outliers amongst the data groups. As the initial DSC results did not allow to successfully determine the printing material, a modified DSC test procedure was performed. This modified procedure was successful in determining the $\mathrm{T}_{\mathrm{g}}$ of the polymer material used for the 3D printing process. Specifically, the $\mathrm{T}_{\mathrm{g}}$ of the polymer was found to be around $-15^{\circ} \mathrm{C}$ to $-17^{\circ} \mathrm{C}$ as shown in Figure 20, thus suggesting that the polymer used for the 3D printing process may be Polypropylene (PP). 


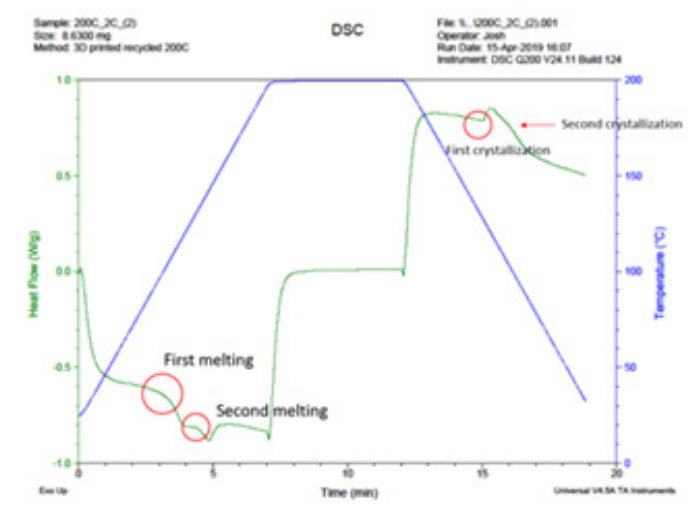

Figure 19: DSC Results Showing Multiple Melting and Crystallization Stages.

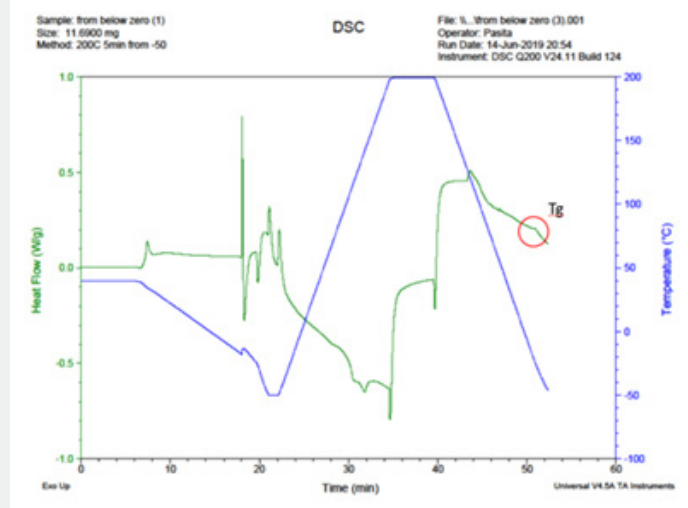

Figure 20: Modified DSC Test Results Showing Tg of Polymer.c

The results from the DMA test showed no definitive $\mathrm{T}_{\mathrm{g}}$ for the specimens in all three graphs as shown in Figure 21. From the data collected, the average storage modulus drop point of the specimen was found to be at $101.12^{\circ} \mathrm{C}$. The average point where loss modulus peaks was $106.86^{\circ} \mathrm{C}$, and the average point where tangent delta was at its peak was $115.31^{\circ} \mathrm{C}$. The lack of a definitive
$\mathrm{T}_{\mathrm{g}}$ can most likely be attributed to the $\mathrm{T}_{\mathrm{g}}$ being below the range of the temperatures tested. However, it can also be indication of the polymer being a blend of different materials, thus causing the $\mathrm{T}_{\mathrm{g}}$ to be potentially overlapped by the melting process. The Grubb test performed for each data group revealed no outliers, while the values appeared to be consistent.

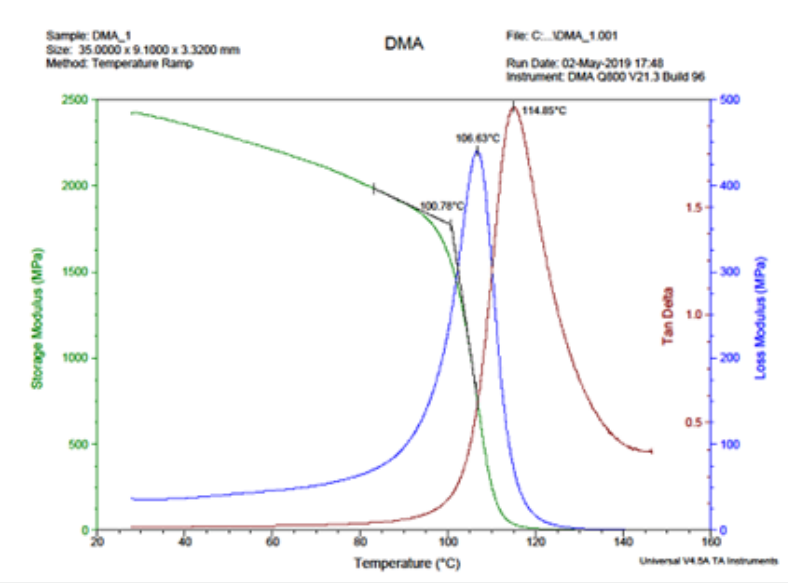

Figure 21: DMA Results Showing Specimen's Melting Temperatures. 


\section{Conclusion}

The study investigated the physical properties, such as void content, fiber content, fiber length, fiber orientation, and curing characteristics, of randomly selected sections of a prototype 3D printed recycled carbon fiber part. The physical properties were analyzed using multiple methods, including image analysis of the specimen's cross-sections and ashes, as well as DSC and DMA tests.

The results of the study found the average void content to be around $1.40 \%$. However, the relatively low void content was inconsistent amongst the beads, thus suggesting that the void consistency throughout the prototype 3D printed recycled carbon fiber part requires better control. The average fiber content of the specimens was approximately $2.26 \%$. Even with the unevenly distributed fibers around the outer edge of the beads, the main concern regarding fiber content, based on the results, is the specimen's low fiber content. The amount of fibers within the component is usually a significant contributor to a component's mechanical properties $[7,8]$. Therefore, the specimen's low fiber content suggests that the associated specimen's mechanical properties will be relatively poor. In addition to the fiber content, another contributing factor to the specimen's mechanical properties is the specimen's fiber length. Previous research has shown that the strength of a component increases as the mean fiber length increases [9]. In this study, the average fiber length within the specimens was found to be around $95.87 \mu \mathrm{m}$. However, the fiber length within the specimens was very inconsistent amongst the beads. This inconsistency and lack of fiber length control will greatly limit the accuracy of the final component's strength and reliability predictions. Similar to the fiber length, the fiber orientation in the specimens was also found to be very inconsistent throughout the beads. Fibers with similar orientations tend to cluster close together in various areas of the bead. The inconsistencies in fiber orientation, analogous to fiber length, will greatly affect the accuracy of the final component's strength and reliability predictions. Research shows that when the fiber orientations of $3 \mathrm{D}$ printed parts are the same as the orientation of the load applied, the strength of the 3D printed part increases [9]. Thus, in order to improve the mechanical properties of the specimens, the fiber orientation inconsistencies need to be addressed.

Lastly, DSC and DMA test results indicate the specimens' $\mathrm{T}_{\mathrm{g}}$ to be around $110^{\circ} \mathrm{C}$. However, the results of the thermal analysis of the DSC and DMA tests did not allow to determine the exact polymer material used in the manufacture of the prototype 3D printed recycled carbon fiber part. The results allowed to eliminate ABS and PLA as possible polymer materials used and identified the possibility of the polymer material being a blend between two different materials. After modifications to the DSC and DMA test procedures, the DSC test was successful in determining the $\mathrm{T}_{\mathrm{g}}$ of the polymer material used for the 3D printing process. Specifically, the $\mathrm{T}_{\mathrm{g}}$ of the polymer was determined to be between $-15^{\circ} \mathrm{C}$ and $-17^{\circ} \mathrm{C}$, thus suggesting that the polymer used for the $3 \mathrm{D}$ printing process could be Polypropylene.

\section{References}

1. Soutis C (2005) Carbon fiber reinforced plastics in aircraft construction. Mater Sci Eng A 412(1-2): 171-176.

2. Soutis C (2005) Fibre reinforced composites in aircraft construction. Prog Aerosp Sci 41(2): 143-151.

3. Song Q Li J, Zeng X (2015) Minimizing the increasing solid waste through zero waste strategy. J Clean Prod 104: 199-210.

4. Greyson J (2007) An economic instrument for zero waste, economic growth and sustainability. J Clean Prod 15(13-14): 1382-1390.

5. Chua CK, Leong KF, Lim CS (2010) Rapid Prototyping: Principles and Applications. In: $3^{\text {rd }}$ (edn.), World Scientific, Singapore.

6. Tian X, Liu T, Wang Q, Dilmurat A, Li D, et al. (2017) Recycling and remanufacturing of 3D printed continuous carbon fiber reinforced PLA composites. J Clean Prod 142(4): 1609-1618.

7. Blanc R, Germain C, Da Costa JP, Baylou P, Cataldi M (2006) Fiber orientation measurements in composite materials. Compos Part A 37(2): 197-206.

8. Tian X, Liu T, Yang C, Wang Q, Li D (2016) Interface and performance of 3D printed continuous carbon fiber reinforced PLA composites. Compos Part A 88: 198-205.

9. Fu SY, Lauke B (1996) Effects of fiber length and fiber orientation distributions on the tensile strength of short-fiber-reinforced polymers. Compos Sci Technol 56(10): 1179-1190.

\section{Your next submission with JuniperPublishers} will reach you the below assets

- Quality Editorial service

- Swift Peer Review

- Reprints availability

- E-prints Service

- Manuscript Podcast for convenient understanding

- Global attainment for your research

- Manuscript accessibility in different formats

( Pdf, E-pub, Full Text, Audio)

- Unceasing customer service

Track the below URL for one-step submission https://juniperpublishers.com/submit-manuscript.php 